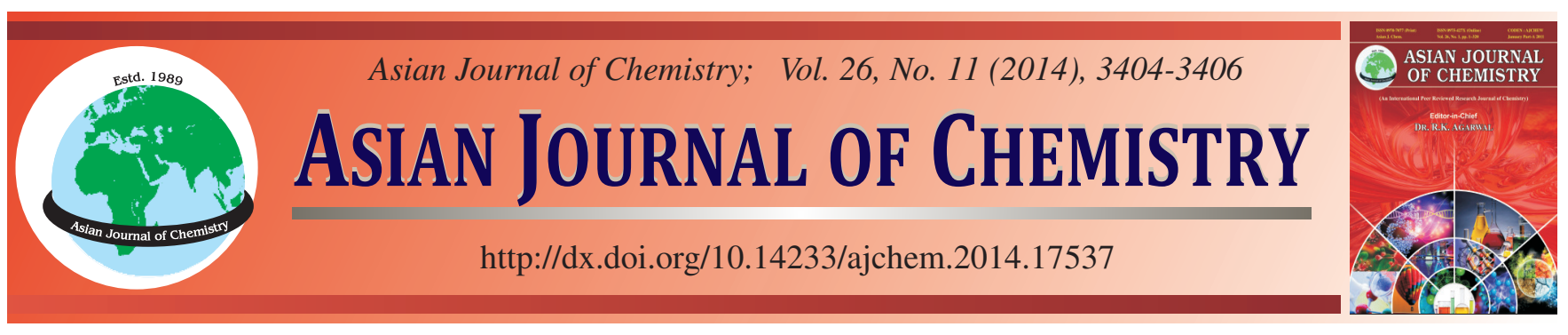

\title{
Hydrolysis Kinetics of Chloroacetic Acid with Sodium Hydroxide Under Strong Alkaline Conditions
}

\author{
WenZe Li ${ }^{1,2}$, Shaoqing Chang ${ }^{2}, \mathrm{XIN}_{\mathrm{CHEN}}{ }^{2}, \mathrm{XuAN} \mathrm{QI}^{2, *}$ and Hong-Bin Sun ${ }^{2, *}$
}

${ }^{1}$ College of Applied Chemistry, Shenyang University of Chemical Technology, Shenyang 110142, P.R. China

${ }^{2}$ College of Science, Northeastern University, Shenyang 110819, P.R. China

*Corresponding author: Tel: +86 24 83671751; E-mail: sunhb@mail.neu.edu.cn

Received: 21 February 2014;

Accepted: 21 April 2014;

Published online: 25 May 2014;

AJC-15259

The hydrolysis of chloroacetic acid and sodium hydroxide is carried out at $45-85^{\circ} \mathrm{C}$ by using equal mole of sodium chloroacetate and alkali. Using reasonable approximation, the hydrolysis reaction is proved to be a second-order reaction when the conversion is less than $95 \%$ and the kinetic rate coefficients are determined. The activate energy is calculated $103 \mathrm{~kJ} \mathrm{~mol}^{-1}$.

Keywords: Hydrolytic kinetic, Chloroacetic acid, Hydrolysis, Reaction rate coefficient.

\section{INTRODUCTION}

Chloroacetic acid (CAA) is an essential compound for carboxymethylation and it is widely used in pharmaceuticals, pesticides, fuel and chemical intermediates ${ }^{1-4}$. It is an indispensable moiety for a lot of important chemicals such as carboxymethyl cellulose, adrenaline, naphthylacetic acid and herbicide 2,4-D. Chloroacetic acid is easily soluble in water with high concentration, so its carboxymethylation is usually carried out in water. Thus, the hydrolysis of chloroacetic acid is an inevitable side reaction. Glycolic acid is the byproduct of the reaction of chloroacetic acid with water, but it is miscible with water and can not be separated in existing technique in low cost. So the manufacture using chloroacetic acid often generates large amount waste water with high COD, the waste water is harmful to the environment because it can not be used in recycling procedure and the harmlessness treatment of it also cost a lot. To inhibit the hydrolysis of chloroacetic acid have double significance: increase the selectivity in carboxymethylation and decrease the amount of waste water. Several reports have described the hydrolysis in a constant $\mathrm{pH}$ value to detail the mechanism $^{5,6}$.

The hydrolysis of chloroacetic acid is not a single reaction. There are four obvious reactions in the chloroacetic acid-water system that is summarized below:

$$
\begin{aligned}
& \mathrm{ClCH}_{2} \mathrm{COO}^{-}+\mathrm{OH}^{-} \rightleftharpoons \mathrm{HOCH}_{2} \mathrm{COO}^{-}+\mathrm{Cl}^{-} \\
& \mathrm{ClCH}_{2} \mathrm{COOH}+\mathrm{OH}^{-} \rightleftharpoons \mathrm{HOCH}_{2} \mathrm{COOH}+\mathrm{Cl}^{-}
\end{aligned}
$$

$$
\begin{aligned}
& \mathrm{ClCH}_{2} \mathrm{COOH}+\mathrm{H}_{2} \mathrm{O} \rightleftharpoons \mathrm{HOCH}_{2} \mathrm{COOH}+\mathrm{HCl} \text { (3) } \\
& \mathrm{ClCH}_{2} \mathrm{COO}^{-}+\mathrm{H}_{2} \mathrm{O} \rightleftharpoons \mathrm{HOCH}_{2} \mathrm{COO}^{-}+\mathrm{HCl} \text { (4) }
\end{aligned}
$$

Because of the diversity of the reactions and their interrelationships, the accurate determination of the kinetic parameter is nearly impossible. Usually, chloroacetic acid is used as a carboxymethylation reagent under strong alkaline environments with high concentration, so the assumption that the eqn. 1 is the primary reaction is reasonable. Therefore, the eqns. 24 are ignored under these conditions, especially in low chloroacetic acid conversion. In this paper, we report kinetic data of the hydrolysis of chloroacetic acid and then we prove the rationality of the approximation mentioned above according to the excellent linear relationship of the data.

The hydrolysis of chloroacetic acid is reported as a secondorder reaction ${ }^{7}$. The mechanism of the reaction is clearly described in equation (1): a chloroacetate ion reacts with a hydroxyl ion in water to give hydroxyacetate ion and chloride ion. According the second-order reaction kinetics, the relationship of substrate concentrations and reaction time obeys the rules described below:

$$
\frac{1}{\mathrm{c}}-\frac{1}{\mathrm{c}_{0}}=\mathrm{kt}
$$

We choose the same concentration of $\mathrm{Cl}-\mathrm{C}$ bond and base, so $3 \mathrm{M}$ aqueous chloroacetic acid and $6 \mathrm{M} \mathrm{NaOH}$ are used as starting substances, as the neutralization of chloroacetic acid consumes equal mole $\mathrm{NaOH}$. The acid and alkaline are put 
into flask and mix quickly then they are bring to the proper temperature. The concentrations (c) are examined at certain times $(\mathrm{t})$ then the $\mathrm{c}-\mathrm{t}$ curves are described.

\section{EXPERIMENTAL}

Typical procedure for the kinetic experiment of chloroacetic acid and $\mathrm{NaOH}$ : in a $100 \mathrm{~mL}$ round bottom flask $3 \mathrm{M}$ aqueous chloroacetic acid and $6 \mathrm{M} \mathrm{NaOH}$ are mixed rapidly then keep at $45^{\circ} \mathrm{C}$. Every $15 \mathrm{~min} 1 \mathrm{~mL}$ reaction mixture is sampled to volumetric flask and then constant to $25 \mathrm{~mL}$ with deionized water. The residual alkaline is titrated with $0.1038 \mathrm{M}$ standard $\mathrm{HCl}$ and the amount of $\mathrm{Cl}^{-}$is titrated with $0.1002 \mathrm{M}$ standard $\mathrm{AgNO}_{3}$ indicated by $\mathrm{K}_{2} \mathrm{CrO}_{4}$. Using the similar method, experiments are carried out at $55,65,75$ and $85^{\circ} \mathrm{C}$. The results are summarized in Table-1.

\section{RESULTS AND DISCUSSION}

The $\mathrm{c}_{0}$ value can not be simply considered as $1.5 \mathrm{M}$ due to the generation of water and the change of total volume because of the high starting concentration. The amount of chloride ion hydrolyzed from $\mathrm{C}-\mathrm{Cl}$ bond and the amount of $\mathrm{HCl}$ added is equal to the initial concentration of chloroacetic acid, so the titration of $\mathrm{Cl}^{-}$ion with standard $\mathrm{AgNO}_{3}$ can measure the $\mathrm{c}_{0}$ and correct the sampling error. The results indicate that the $\mathrm{c}_{0}$ is $1.33 \mathrm{~mol} / \mathrm{L}$ and the sampling error is less than $1.6 \%$. The experimental data is treated as second-order reaction program, $\left(1 / \mathrm{c}-1 / \mathrm{c}_{0}\right)$ on $\mathrm{t}$ should plot a straight line through the origin. Actually, we get a straight line with a perfect linearly dependent coefficient $\left(\mathrm{R}^{2}=1.00\right)$. The straight line not exactly goes through the origin, may be the presence of a certain measurement errors at time 0 . Under this reaction conditions, the conversion of chloroacetic acid is less than $50 \%$ at $45^{\circ} \mathrm{C}$ for $3 \mathrm{~h}$. This proves that the approach mentioned above gives good agreement to a second-order reaction, especially at low temperature and low conversion.

To control of temperature exactly is necessary in kinetic experiment. During the operating period, we use a precise temperature-controlling heater with magnetic stirrer that can provide wonderful heat and mass transfer so the fluctuation is no more than $0.5^{\circ} \mathrm{C}$. But we use the high concentrated solution as the starting reactant, the mixing of chloroacetic acid and $\mathrm{NaOH}$ release a lot of heat that raises the reaction mixture's temperature rapidly and the system can not establish heat

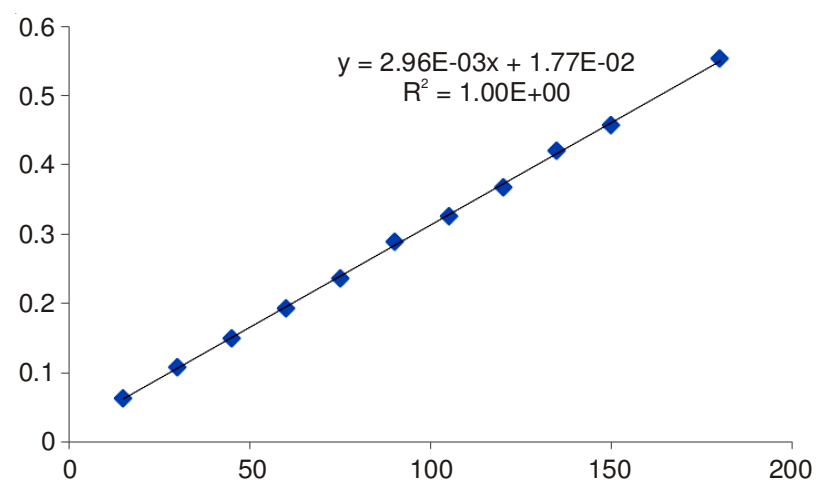

Fig. 1. Kinetic relationship of concentration of chloroacetic acid with time (c-t) at $45^{\circ} \mathrm{C}$

steady-state during the beginning $10 \mathrm{~min}$. The settlement is to measure the rise of temperature and then take care of it. By mixing the $25^{\circ} \mathrm{C}$ thermostated chloroacetic acid and $\mathrm{NaOH}$ rapidly and then make the temperature-time curve in general calorimetry, we find the adiabatic temperature rise is $20^{\circ} \mathrm{C}$. In the next experiment we pre-thermostat the chloroacetic acid and $\mathrm{NaOH}$ to $20^{\circ} \mathrm{C}$ below the target temperature, then mix them rapidly. The system establishes heat steady-state in a very short time after the mixing and this gives wonderful experimental data with perfect linear relationship.

According to the slope of the line in Fig. 2, we calculate the apparent reaction rate coefficients $(\mathrm{k})$ of $45,55,65,75$ and $85^{\circ} \mathrm{C}$ that are listed in Table-2.

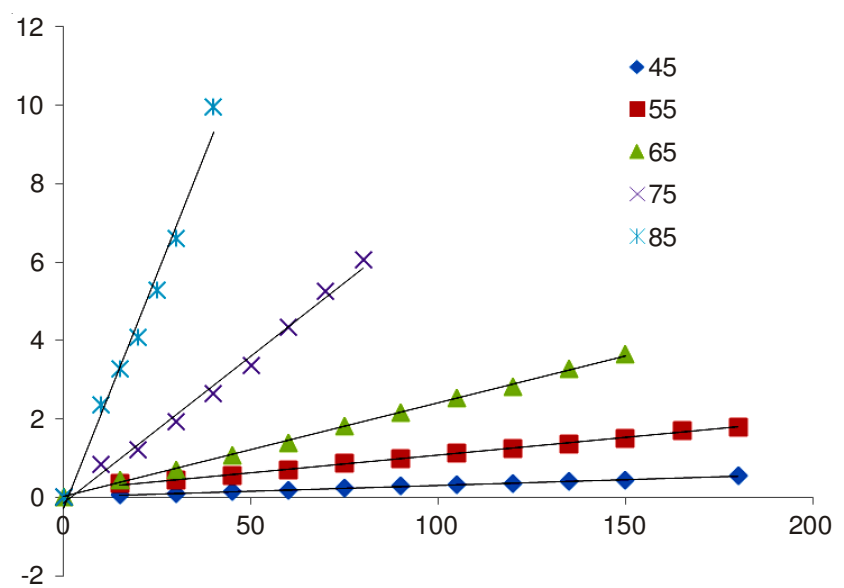

Fig. 2. Kinetic relationship of concentration of chloroacetic acid with time (c-t) at $45-85^{\circ} \mathrm{C}$

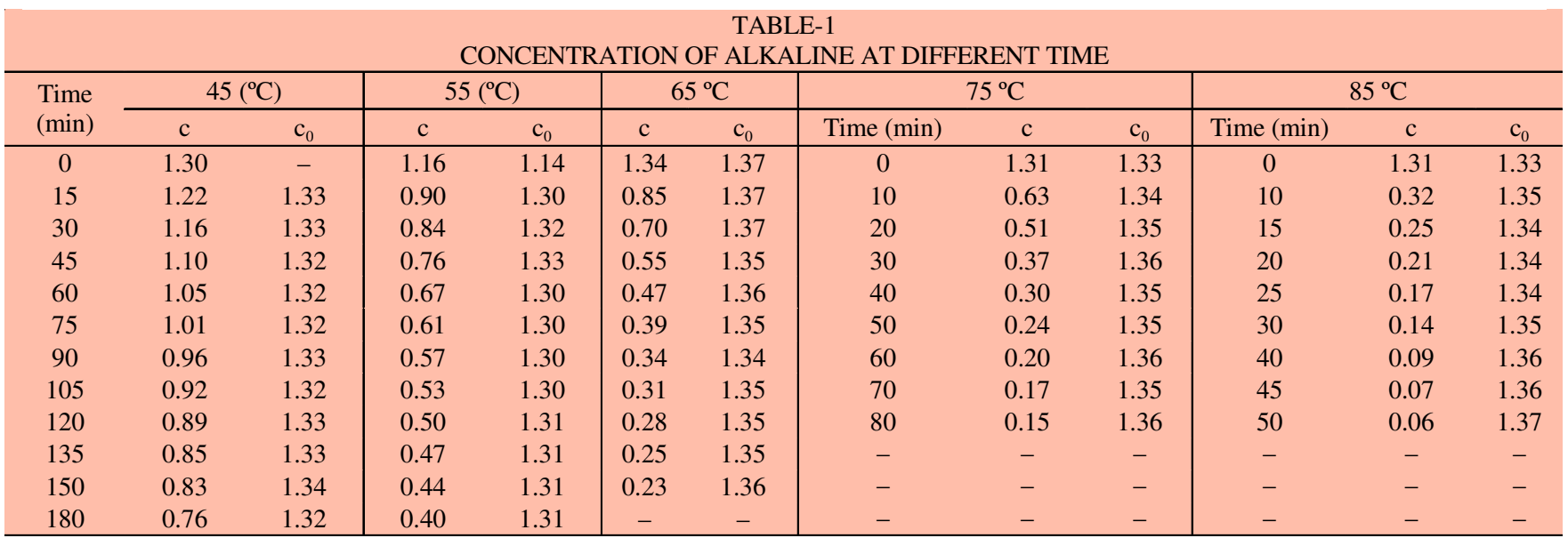




\begin{tabular}{cccccc}
\hline \multicolumn{5}{c}{ TABLE-2 } \\
APPARENT HYDROLYSIS RATE \\
COEFFICIENT OF CAA AT 45-85 ${ }^{\circ} \mathrm{C}$ \\
\hline $\mathrm{t}\left({ }^{\circ} \mathrm{C}\right)$ & 45 & 55 & 65 & 75 & 85 \\
\hline $\mathrm{k}\left(\mathrm{mol}^{-1} \mathrm{~L} \mathrm{~min}^{-1}\right)$ & 0.00296 & 0.00898 & 0.0239 & 0.075 & 0.240 \\
\hline
\end{tabular}

Then we can calculate the activation energy through these data by the Arrhenius equation:

$$
\ln \mathrm{k}=-\frac{\mathrm{E}_{\mathrm{a}}}{\mathrm{RT}}+\mathrm{C}
$$

The experimental reaction rate coefficients $(\mathrm{k})$ and reaction temperature give a wonderful match to the Arrhenius equation with good linearship $\left(\mathrm{R}^{2}=0.9965\right.$, Fig. 3$)$. The calculated activation energy is $103 \mathrm{~kJ} \mathrm{~mol}^{-1}$.

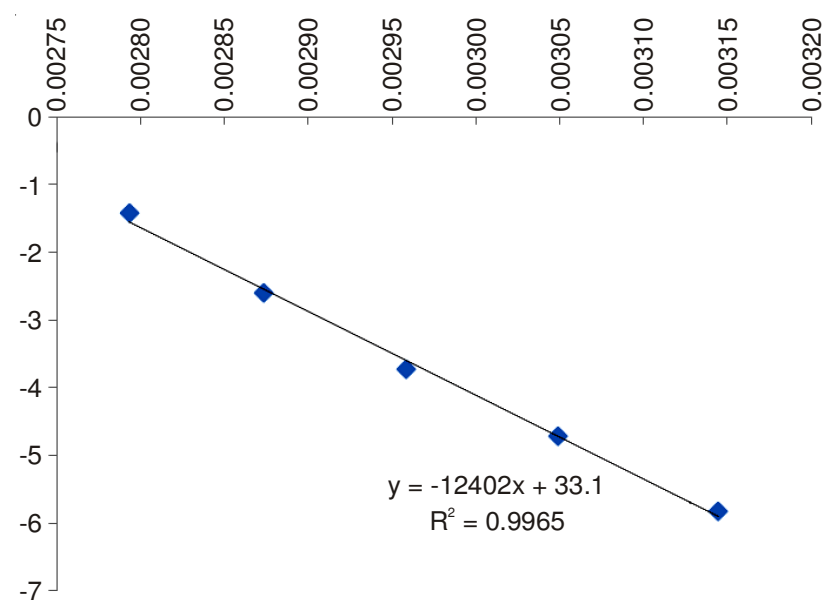

Fig. 3. Chloroacetic acid hydrolysis $\ln \mathrm{k} \sim 1 / \mathrm{T}$ fitting to Arrhenius equation at $45-85^{\circ} \mathrm{C}$. T means Kelvin's temperature, which equals to centigrade degree plus 273.15

The temperature is a key factor for the hydrolysis of chloroacetic acid. The conversion of chloroacetic acid is no more than $10 \%$ even under strongly alkaline evironment for
$15 \min$ at $45^{\circ} \mathrm{C}$, but it increases to over $80 \%$ when the reaction temperature is raised to $85^{\circ} \mathrm{C}$. from the experimantal data we can recogonize that when the conversion of chloroacetic acid is more than $90 \%$ after $40 \mathrm{~min}$ at $85^{\circ} \mathrm{C}$, the concentration variation remains in line with second-order kinetic equation. But when the conversion is more than $95 \%$, more side reaction occur so the c-t curve begin to deviate the second-order reaction's straight line. This indicates that in the hydrolysis system of chloroacetic acid the reaction of chloroacetic acid and hydroxyl ion is the major reaction and the other side reactions can be ignored when the conversion is less than $95 \%$.

\section{Conclusion}

In summary, we determine the kinetic rate coefficient of chloroacetic acid hydrolysis and calculate this reaction's activate energy. The reaction is a second-order reaction and the activate energy is $103 \mathrm{~kJ} / \mathrm{mol}$.

\section{ACKNOWLEDGEMENTS}

Financial support from the National Natural Science Foundation of China (21003018) and the Doctoral Starting up Foundation of Liaoning Province (20121071) are gratefully acknowledged.

\section{REFERENCES}

1. A.B.M. Fakrul Alam and M.I.H. Mondal, J. Appl. Polym. Sci., 128, 1206 (2013).

2. D.C. Dash, R.K. Mohapatra, S. Ghosh and P. Naik, J. Indian Chem. Soc., 86, 121 (2009).

3. I.O. Lebedyeva, M.V. Povstyanoy, A.B. Ryabitskii and V.M. Povstyanoy, J. Heterocycl. Chem., 47, 368 (2010).

4. S. S. Vaghani, M. M. Patel, C. S. Satish, K. M. Patel and N. P. Jivani, Curr. Drug Deliv., 9, 628 (2012).

5. L.F. Berhenke and E.C. Britton, Ind. Eng. Chem., 38, 544 (1946).

6. S.C. Yu, M.L. Lu and R.N. Xu, Huadong Shifan Daxue Xuebao, 70 (1984) (in Chinese)

7. J. Y. Xu and H. P. Wang, Anhui Hua Gong, 36 (1990) (in Chinese). 